\title{
Nosodes in immunisation: symptom not aetiological similimum
}

\author{
Isaac Golden
}

Federation University, Australia

\section{Dear Editor,}

Teixeira [1] provides a scholarly review of Hahnemann's and Kent's writings, regularly switching between the treatment of disease and prevention. The fatal flaw in Teixeira's lengthy rebuttal is his incorrect presumption that nosodes are selected "on the principle of etiological identity". In an appropriate homoeoprophylaxis program nosodes are selected, and they work, because they produce symptoms that are similar to the symptoms we wish to prevent in our patients, and thus when properly selected are based squarely on the Law/Principle of Similars. This is why a remedy made from a different strain of organism will work if the symptom pattern of that strain of disease is similar to the symptom pattern of a different strain. If the symptoms don't match, the remedy will not work. All the quotes aside, his rebuttal is based on this presumption.

I suspect that a lengthy point-by-point reply would be unproductive, so I offer just five further observations.

1. The term homoeoprophylaxis (HP) was first used by Burnett in 1884 to refer to "the prevention of disease according to the law of similars". I have yet to hear a better definition. Isoprophylaxis is once again Teixeira's opinion of what HP using nosodes should be called.

2. Provings, whilst essential, are not the only way to gain knowledge of the symptoms capable of being produced in a healthy person by a substance.

3. My own limited research is one small part of a much larger evidence base supporting HP. The totality of evidence is what matters. Reliance on RCT's with their significant inbuilt flaws is not necessary to definitively substantiate the safety and effectiveness of HP (or of homeopathy in general).

4. It is unnecessary to wait until a number of people fall ill to offer HP (as is required if only GE remedies are used). Appropriately selected nosodes can (and do) provide protection in a wide variety of practical situations.

5. Homeopathic practitioners have a very simple choice. They can look at what evidence is available regarding HP and accept it or reject it. If they accept it then they can, with appropriate confidence, offer HP to their patients who are requesting safe and reasonably effective protection against targeted infectious diseases. There is no need to wait for more provings of nosodes, no need to wait for RCT's (although both will be welcome if and when they arrive). We have sufficient evidence now to act in an appropriate and ethical manner. 
I am content that my use of HP (including both nosodes and GE remedies) over 30 years has contributed to the wellbeing of tens of thousands of children who have used my programs, if only because it has lessened the likelihood of them contracting targeted infectious diseases and has allowed them to avoid the possibility of long-term vaccine damage. To me it stands alongside vaccination as an immunisation option for parents to choose if they wish.

Finally, and after apparently supporting GE-based immunisation, Teixeira passionately demands that children be vaccinated. Which is it? I respectfully request Teixeira to demonstrate "the abundant scientific evidence that documents the safety" of vaccines by quoting one substantive long-term study comparing the holistic health of fully vaccinated and fully unvaccinated children. Until such studies are published, long-term safety claims are no more than convenient "spin" by vaccine manufacturers and their supporters. The true value of HP is best seen in the light of such studies - or their absence.

[1] Teixeira MZ. Isoprophylaxis is neither homeoprophylaxis nor homeopathic immunization, but isopathic immunization unsupported by the homeopathic epistemological model: a response to Golden. Int J High Dilution Res [online]. 2014 [cited 2014 April 1]; 13(46): 54-82. Available from: http://www.feg.unesp.br/ ojs/index.php/ijhdr/article/view/707/687

\section{(c)) BY-NC-ND Licensed to GIRI}

Received: April 01 ${ }^{\text {st }} 2014$; Revised: April 15 2 th 2014 ; Published: September 30th 2014.

Correspondence author: Isaac Golden, http://www.homstudy.net, admin@homstudy.net

How to cite this article: Golden I. Nosodes in immunisation: symptom not aetiological similimum [Letter to the Editor]. Int J High Dilution Res [online]. 2014 [cited YYYY Month dd]; 13(48): 145-146. Available from: http://www.feg.unesp.br/ ojs/index.php/ijhdr/article/view/712/725 